\title{
Microcirculatory dysfunction and dead-space ventilation in early ARDS: a hypothesis-generating observational study
}

\author{
Gustavo A. Ospina-Tascón ${ }^{1,2^{*}}$, Diego F. Bautista ${ }^{1}$, Humberto J. Madriñán ${ }^{1}$, Juan D. Valencia', \\ William F. Bermúdez ${ }^{1}$, Edgardo Quiñones ${ }^{1}$, Luis Eduardo Calderón-Tapia', Glenn Hernandez ${ }^{3}$, Alejandro Bruhn ${ }^{3}$ \\ and Daniel De Backer ${ }^{4}$
}

\begin{abstract}
Background: Ventilation/perfusion inequalities impair gas exchange in acute respiratory distress syndrome (ARDS), Although increased dead-space ventilation $\left(V_{D} / V_{T}\right)$ has been described in ARDS, its mechanism is not clearly understood. We sought to evaluate the relationships between dynamic variations in $V_{D} / V_{T}$ and extra-pulmonary microcirculatory blood flow detected at sublingual mucosa hypothesizing that an altered microcirculation, which is a generalized phenomenon during severe inflammatory conditions, could influence ventilation/perfusion mismatching manifested by increases in $V_{D} / V_{T}$ fraction during early stages of ARDS.
\end{abstract}

Methods: Forty-two consecutive patients with early moderate and severe ARDS were included. PEEP was set targeting the best respiratory-system compliance after a PEEP-decremental recruitment maneuver. After 60 min of stabilization, hemodynamics and respiratory mechanics were recorded and blood gases collected. $V_{D} / V_{T}$ was calculated from the $\mathrm{CO}_{2}$ production $\left(\mathrm{V}_{\mathrm{CO}_{2}}\right)$ and $\mathrm{CO}_{2}$ exhaled fraction $\left(\mathrm{F}_{\mathrm{ECO}_{2}}\right)$ measurements by volumetric capnography. Sublingual microcirculatory images were simultaneously acquired using a sidestream dark-field device for an ulterior blinded semi-quantitative analysis. All measurements were repeated $24 \mathrm{~h}$ after.

Results: Percentage of small vessels perfused (PPV) and microcirculatory flow index (MFI) were inverse and significantly related to $V_{D} / V_{T}$ at baseline (Spearman's rho $=-0.76$ and $-0.63, p<0.001 ; R^{2}=0.63$, and $0.48, p<0.001$, respectively) and $24 \mathrm{~h}$ after (Spearman's rho $=-0.71$, and $-0.65 ; p<0.001 ; R^{2}=0.66$ and $0.60, p<0.001$, respectively). Other respiratory, macro-hemodynamic and oxygenation parameters did not correlate with $V_{\mathrm{D}} / V_{\mathrm{T}}$. Variations in PPV between baseline and $24 \mathrm{~h}$ were inverse and significantly related to simultaneous changes in $V_{\mathrm{D}} / V_{\mathrm{T}}$ (Spearman's $r h o=-0.66$, $\left.p<0.001 ; R^{2}=0.67, p<0.001\right)$.

Conclusion: Increased heterogeneity of microcirculatory blood flow evaluated at sublingual mucosa seems to be related to increases in $V_{D} / V_{T}$, while respiratory mechanics and oxygenation parameters do not. Whether there is a cause-effect relationship between microcirculatory dysfunction and dead-space ventilation in ARDS should be addressed in future research.

Keywords: Acute respiratory distress syndrome, Dead-space ventilation, $V_{D} / V_{T}$, Ventilation/perfusion mismatch, Microcirculation, Microcirculatory blood flow

\footnotetext{
*Correspondence: gusospin@gmail.com

${ }^{1}$ Department of Intensive Care, Fundación Valle del Lili - Universidad ICESI, Av. Simón Bolívar Cra. 98, Cali, Valle del Cauca, Colombia Full list of author information is available at the end of the article
}

\section{Background}

Acute respiratory distress syndrome (ARDS) is a form of acute respiratory failure characterized by pulmonary inflammation leading to increased capillary and 
epithelial permeability, with subsequent loss of aerated lung tissue and increased lung stiffness [1]. These alterations lead to imbalances between ventilation and perfusion relationships, which finally result in hypoxemia and impaired carbon dioxide clearance.

An optimal ventilation-to-perfusion $\left(V_{\mathrm{A}} / Q\right)$ ratio $\left(0.1<V_{\mathrm{A}} / Q<10\right)$ is necessary to ensure a normal gas exchange [2-4]. Typically, it has been considered that pulmonary perfusion in ARDS occurs in non-ventilated $\left(V_{\mathrm{A}} / Q<0.005\right)$ or poorly ventilated $\left(0.005<V_{\mathrm{A}} / Q<0.1\right)$ lung units, which, in turn, results in vasoconstriction of perfusing arterioles [5]. Such $V_{\mathrm{A}} / Q$ mismatch in some lung regions in which perfusion largely exceeds ventilation, account for hypoxemia, which is the clinical hallmark of ARDS $[1,6$, 7]. Nevertheless, distribution of ventilation to poorly perfused $\left(10<V_{\mathrm{A}} / Q<100\right)$, severely hypoperfused $\left(V_{\mathrm{A}} / Q>100\right)$ or non-perfused $\left(V_{\mathrm{A}} / Q \sim \infty\right)$ lung units might also occur in patients with ARDS [3] and indeed, increases in $V_{\mathrm{D}} / V_{\mathrm{T}}$ have been strongly related with adverse clinical outcomes [8-10]. Importantly, high $V_{\mathrm{A}} / Q$ and $V_{\mathrm{A}} / Q \sim \infty$ ratios corresponding to lung regions where ventilation largely exceeds perfusion, account for carbon dioxide retention [5]. Increases in high $V_{\mathrm{A}} / Q$ and/or dead-space lung units have been classically attributed to alveolar overdistention with the subsequent compression of intra-alveolar vessels in the non-dependent lung areas $[8,11]$. Nevertheless, increased dead-space ventilation has also been described in patients subjected to protective ventilation strategies with low plateau pressures $[9,10]$, which suggest that mechanisms different to alveolar overdistention should be implied.

In normal conditions, the heterogeneity of systemic microcirculatory blood flow distribution is negligible [12]. Nevertheless, severe inflammation can induce microcirculatory alterations $[13,14]$ determining alterations in oxygen extraction capabilities by the tissues and contributing to the development of multiple organ dysfunction [14]. Although there are many technical limitations to directly evaluate pulmonary microcirculation [15], heterogeneity of microvascular blood flow at pulmonary level could contribute to imbalances between ventilation and perfusion relationships. Thus, considering microcirculatory dysfunction during inflammatory conditions as a generalized phenomenon, which may involve systemic and pulmonary vascular beds, we hypothesized that alterations in microvascular blood flow distribution evaluated at the sublingual mucosa as representative of an extra-pulmonary territory could be related to variations in dead-space ventilation $V_{\mathrm{D}} / V_{\mathrm{T}}$ during early phases of moderate and severe ARDS.

\section{Methods}

This prospective observational study was conducted in a 90-bed mixed ICU from a university hospital. The local Ethical and Biomedical Research Committee approved the study (Fundación Valle del Lili EBRC protocol number: 0628; approval number: 038-7, 2013). A written informed consent was waived as no invasive procedures or new interventions were used. We daily screened all patients under mechanical ventilation in the ICU during a 24-month period, searching for those with moderate and severe ARDS. To avoid the selection of cases with transitory hypoxemia simulating ARDS, patients were enrolled only after successfully completing a two-step selection process $[16,17]$ : (a) first, patients mechanically ventilated through an endotracheal tube with a PEEP $\geq 5$ and $\mathrm{FiO}_{2} \geq 0.5$ for at least $12 \mathrm{~h}$ and meeting the moderate and severe ARDS criteria according to Berlin Consensus definitions [1] were declared potentially eligible; (b) then, potential candidates were subjected to a $\mathrm{FiO}_{2}$ trial at 1.0 while maintaining $\mathrm{PEEP} \geq 10$ (to sustain a $\mathrm{SpO}_{2} \geq 88 \%$, but ensuring peak inspiratory and plateau pressures $<35$ and $28 \mathrm{cmH}_{2} \mathrm{O}$, respectively) for at least $30 \mathrm{~min}$, after which, new arterial blood gases were collected. Those patients maintaining a $\mathrm{PaO}_{2} / \mathrm{FiO}_{2} \leq 200$ after such PEEP/ $\mathrm{FiO}_{2}$ trial and with $<48 \mathrm{~h}$ of evolution of ARDS were finally included. The exclusion criteria were: $<18$ years of age, pregnancy state, history of neuromuscular diseases, moderate and severe COPD (defined as $\mathrm{FEV}_{1}<80 \%$ predicted); history of intubation due to COPD exacerbation, receiving domiciliary oxygen or long-term use of steroids because COPD; history of congestive heart failure or any acute ischemic cardiac condition. A patient was also excluded when limitation of therapeutic effort orders were given.

\section{Study protocol}

After fulfilling the two-step selection process, patients selected were connected to a mainstream $\mathrm{CO}_{2}$ sensor and this in turn to a volumetric capnography module (Infinity $\mathrm{EtCO}_{2}+$ respiratory mechanics module, Dräger Medical Systems, Telford, USA). Mechanical ventilation parameters were adjusted after a stepwise alveolar recruitment maneuver, as it will be detailed later. After a $60 \mathrm{~min}$ of stabilization period, we started capnography measurements while sublingual microcirculatory images were simultaneously acquired, such as detailed thereafter. A new set of measurements was obtained $24 \mathrm{~h}$ after. Arterial and mixed venous blood samples (when available) were drawn for gases analysis (ABL300, Radiometer; Copenhagen, Denmark) at T0 and $24 \mathrm{~h}$ after (T24). In all the cases, the attending physicians decided on the type of hemodynamic monitoring to use. Complete respiratory 
and hemodynamic parameters were also registered simultaneously.

\section{Recruitment maneuvers, PEEP adjustment and mechanical ventilation settings}

At the time in which this study was performed, the local protocol included an initial recruitment maneuver to adjust PEEP in patients with severe ARDS. Thus, patients were subjected to a stepwise recruitment maneuver with progressive PEEP increases until a peak pressure of $50 \mathrm{cmH}_{2} \mathrm{O}$ while maintaining a driving pressure of 15 $\mathrm{cmH}_{2} \mathrm{O}$, as described elsewhere $[18,19]$. Once obtained the maximal peak pressure, it was sustained during $2 \mathrm{~min}$ whereupon a decremental PEEP titration trial was conducted in steps of $2 \mathrm{cmH}_{2} \mathrm{O}$ at 2 min interval from 22 to $8 \mathrm{cmH}_{2} \mathrm{O}$ registering the corresponding compliance of the respiratory system $\left(C_{\mathrm{RS}}\right)$. After such a PEEP titration, a new alveolar recruitment was performed until a peak pressure of $50 \mathrm{cmH}_{2} \mathrm{O}$ while maintaining a driving pressure of $15 \mathrm{cmH}_{2} \mathrm{O}$ during $1 \mathrm{~min}$, to finally adjust the definitive ventilatory settings. Definitive PEEP was set at the corresponding best $C_{\mathrm{RS}}$ plus $2 \mathrm{~cm} \mathrm{H}_{2} \mathrm{O}$. If falls in $\mathrm{C}_{\mathrm{RS}}$ were observed in two consecutive downsteps, then the PEEP level was set at the highest compliance plus 2 $\mathrm{cmH}_{2} \mathrm{O}$. According to the local protocol, the recruitment maneuver was stopped if one or more of following signs were observed: heart rate $>150$ or $<60 \mathrm{bpm}$; decrease of mean arterial pressure $<65 \mathrm{mmHg}$ or systolic pressure $<90 \mathrm{mmHg}$; acute atrial fibrillation, atrial flutter or ventricular tachycardia.

Thereafter, mechanical ventilation was set in volumecontrolled mode or in pressure-controlled, according to the selection of the attending physician. In the first case, ventilation was set at $\mathrm{Vt}$ of $6 \mathrm{ml} / \mathrm{kg}$ of predicted body weight maintaining plateau pressures $<28 \mathrm{cmH}_{2} \mathrm{O}$, flow of $60 \mathrm{l} / \mathrm{min}$, inspiratory pause of $0.5 \mathrm{~s}, I: E$ ratio of $1: 1$ to $1: 2$, respiratory rate to match the minute ventilation previous to the recruitment maneuver, $\mathrm{FiO}_{2}$ necessary for $\mathrm{SpO}_{2} \geq 90$ and $\leq 95 \%$ and PEEP adjusted as indicated above. If plateau pressures were $>28 \mathrm{cmH}_{2} \mathrm{O}$, then $\mathrm{Vt}$ was reduced to a minimum of $4 \mathrm{ml} / \mathrm{kg}$ of predicted body weight. For those ventilated in pressure-controlled mode, driving pressure was adjusted to maintain $\mathrm{Vt} 6 \mathrm{ml} / \mathrm{kg}$ of predicted body weight (or less if $\mathrm{Vt} / C_{\mathrm{RS}}>18$ ), I:E ratio 1:1 to $1: 2$, minute ventilation matching that previous to the recruitment maneuver, peak inspiratory pressure $\leq 35$ $\mathrm{cmH}_{2} \mathrm{O}$, and $\mathrm{FiO}_{2}$ and PEEP adjusted as indicated above.

\section{Pulmonary dead-space fraction measurements}

After an automatic purge and calibration procedure, a mainstream $\mathrm{CO}_{2}$ sensor was placed between the ventilator circuit and the patient connection. This sensor was in turn connected to a volumetric capnography module (Infinity $\mathrm{EtCO}_{2}$ + respiratory mechanics module, Dräger Medical Systems, Telford, USA). After selection of the ventilator settings, a $60 \mathrm{~min}$ of stabilization period was allowed before to start the measurements. Data trend for $\mathrm{CO}_{2}$ production $\left(V_{\mathrm{CO}_{2}}\right)$ and exhaled minute ventilation $\left(V_{\mathrm{E}}\right)$ were averaged over 5 min. $V_{\mathrm{CO}_{2}}$ measurements were obtained at standard temperature and pressure, and dry (STPD), whereby a correction factor of $0.863 \mathrm{mmHg} \mathrm{l} / \mathrm{ml}$ was used to convert to body temperature, and pressure, saturated (BTPS). The fraction of exhaled $\mathrm{CO}_{2}\left(F_{\mathrm{ECO}_{2}}\right)$ was calculated dividing the $V_{\mathrm{CO}_{2}}$ by the $V_{\mathrm{E}}$ (Eq. 1):

$$
F_{\mathrm{ECO}_{2}}=\frac{V_{\mathrm{CO}_{2}}}{V_{\mathrm{E}}} \text {. }
$$

Exhaled $\mathrm{CO}_{2}$ pressure $\left(P_{\mathrm{ECO}_{2}}\right)$ was then calculated as the product between the $F_{\mathrm{ECO}_{2}}$ and the barometric pressure minus the water vapor pressure (Eq. 2):

$$
P_{\mathrm{ECO}_{2}}=F_{\mathrm{ECO}_{2}} \cdot\left(P_{\mathrm{B}}-47\right) \text {, }
$$

where $P_{\mathrm{B}}$ corresponds to the local barometric pressure (i.e., $682 \mathrm{mmHg}$ ). Subsequently, $V_{\mathrm{D}} / V_{\mathrm{T}}$ was calculated by the Enghoff modification of the Bohr equation (Eq. 3):

$$
\frac{V_{\mathrm{D}}}{V_{\mathrm{T}}}=\left(P_{\mathrm{aCO}_{2}}-P_{\mathrm{ECO}_{2}}\right) / P_{\mathrm{aCO}_{2}} .
$$

All measurements of $V_{\mathrm{CO}_{2}}$ performed by the module were automatically corrected for circuit compression, as described elsewhere [20].

\section{Sublingual microcirculation assessment}

A sidestream dark-field (SDF) imaging device (Micro Scan; MicroVision Medical, Amsterdam, the Netherlands) was used to explore the sublingual microcirculation simultaneously to dead-space fraction measurements, ventilatory mechanics and oxygenation parameters at both inclusion and $24 \mathrm{~h}$ after. A cutoff value of $20 \mu \mathrm{m}$ was used to classify vessels as large or small. Continuous flows were considered as normal while intermittent and stopped flows were considered as abnormal. According to the consensus for the evaluation of microcirculation, we calculated the proportion of small vessels perfused (PPV), the total vascular density (TCD) and the functional capillary density (FCD) [21]. A heterogeneity index of microcirculatory blood flow was also calculated as the difference between maximal and minimal PPV values in five different mucosa areas divided by its own mean value (see Additional file 1). Additionally, we reported the microvascular flow index (MFI). A detailed description about microcirculatory blood flow assessment is provided in Additional file 1. 


\section{Statistical analysis}

Sample size calculation is described in Additional file 1 . Distribution of data was tested using the KolmogorovSmirnov test. Non-parametric test for related samples were used to evaluate the differences on hemodynamic, respiratory, capnometry and microcirculatory blood flow parameters between baseline and $24 \mathrm{~h}$ after. The relationships between the $V_{\mathrm{D}} / V_{\mathrm{T}}$, percentage of small vessels perfused (PPV), and microcirculatory blood flow index (MFI) were evaluated by the Spearman rho test. Other bivariate correlations between $V_{\mathrm{D}} / V_{\mathrm{T}}, \mathrm{PaO}_{2} / \mathrm{FiO}_{2}$, and respiratory mechanics were also performed using Spearman rho test. Additionally, simple linear regression models with linear and quadratic terms and their respective coefficients of determination $\left(R^{2}\right)$ were used to evaluate the relationship between each microcirculatory, respiratory mechanics or oxygenation parameter and the $V_{\mathrm{D}} / V_{\mathrm{T}}$ at both baseline and $24 \mathrm{~h}$ after.

Finally, we calculated the delta of variation of $V_{\mathrm{D}} / V_{\mathrm{T}}$ and PPV measurements between baseline and $24 \mathrm{~h}$ after. Then, a Spearman rho was used to evaluate the correlation between $V_{\mathrm{D}} / V_{\mathrm{T}}$ and PPV dynamic variations from baseline to day-1. Furthermore, a simple linear regression model with quadratic term and its respective coefficient of determination $\left(R^{2}\right)$ was used to evaluate the relationship between variations in PPV and $V_{\mathrm{D}} / V_{\mathrm{T}}$ from baseline to $24 \mathrm{~h}$ after. Data are presented as median [percentiles 25-75]. A $p$ value $\leq 0.05$ (2-tailed) was considered significant.

\section{Results}

A total of 42 patients with moderate and severe ARDS were included in the study. A complete flowchart detailing the selection process is shown in Additional file 1: Figure S1, while a STROBE statement checklist for observational studies is provided in Additional file 1: Table S1. Mortality at day- 28 and day- 90 were $31 \%$ and $45.2 \%$, respectively. The ICU length of stay was 18.0 [11.8-26.3] days. General characteristics are presented in Table 1, while hemodynamics, respiratory mechanics, blood gases analysis, pulmonary dead-space fraction and microcirculatory blood flow parameters at baseline and $24 \mathrm{~h}$ after are presented in Table 2. We observed an inverse and significant relationship between PPV and $V_{\mathrm{D}} / V_{\mathrm{T}}$ at both baseline (Spearman rho $=-0.76, p<0.001 ; R^{2}=0.63$, $p<0.001$ ) and $24 \mathrm{~h}$ after (Spearman rho $=-0.71$, $p<0.001 ; R^{2}=0.66, p<0.001$ ) (Fig. 1a, b). Similar findings were observed between $V_{\mathrm{D}} / V_{\mathrm{T}}$ and the microcirculatory flow index at baseline (Spearman rho $=-0.63$, $\left.p<0.001 ; R^{2}=0.48, p<0.001\right)$ and $24 \mathrm{~h}$ after (Spearman rho $=-0.65, p<0.001 ; R^{2}=0.60, p<0.001$ ) (Fig. 1c, d). There were no significant correlations between $V_{\mathrm{D}} / V_{\mathrm{T}}$
Table 1 General characteristics

\begin{tabular}{lc}
\hline & All patients \\
\hline Age & $48(33-63)$ \\
Sex, male (\%) & $24(57.1)$ \\
APACHE II & $21.5(17.027 .3)$ \\
SOFA, day 1 & $11.0(7.8-13.3)$ \\
Coexisting conditions & \\
Hypertension & $8(19.0)$ \\
Diabetes & $5(11.9)$ \\
Hepatic disease & $5(13.2)$ \\
Chronic renal failure & $3(7.3)$ \\
Cancer & $6(14.3)$ \\
Immunosuppression & $6(14.3)$ \\
BMI (kg/m ${ }^{2}$ ) & $20.7(20.3-22.7)$ \\
Risk factors for ARDS & \\
Sepsis & $28(66.7)$ \\
Trauma & $5(13.2)$ \\
Pneumonia & $13(34.2)$ \\
Gastric aspiration & $6(15.8)$ \\
Other & $11(28.9)$ \\
Vasopressors, $n$ (\%) & $26(61.9)$ \\
Steroids, $n$ (\%) & $15(35.7)$ \\
TRR, $n$ (\%) & $8(19.5)$ \\
Prone position, $n$ (\%) & $10(23.8)$ \\
Muscular paralysis & $34(80.9)$ \\
Time since ICU admission to ARDS onset, hours & $96(24-168)$ \\
Cumulated resuscitation fluids, ml & $2.300(1.075-4.735)$ \\
Total cumulative fluids at ARDS diagnosis, ml & $6.361(2.182-13.023)$ \\
Mortality & \\
At day 28 & $13(31.0)$ \\
At day 90 & $19(45.2)$ \\
\hline & \\
\hline & \\
\hline
\end{tabular}

and other respiratory mechanics and oxygenation parameters (Fig. 2, Additional file 1: Table S2).

A significant relationship was observed between the variation in $V_{\mathrm{D}} / V_{\mathrm{T}}$ and the percentage of variation of PPV from baseline measurements to $24 \mathrm{~h}$ after (Spearman rho $=-0.66, p<0.001 ; R^{2}=0.67, p<0.001$ ) (Fig. 3, Additional file 1: Figure S2). Additional information about survivors and non-survivors at day-90 is provided in Additional file 1: Table S3.

\section{Discussion}

After simultaneous calculation of dead-space fraction by volumetric capnography and exploration of sublingual microcirculation by the SDF technique during the early stages of moderate and severe ARDS, we retrieved two hypothesis-generating observations: (a) $V_{\mathrm{D}} / V_{\mathrm{T}}$ is inverse and significantly related with sublingual microcirculatory blood flow distribution, while PEEP levels, respiratory airway pressures, $\mathrm{PaO}_{2} / \mathrm{FiO}_{2}$ and lung strain surrogates 
Table 2 Hemodynamics, respiratory mechanics, blood gases analysis, $V_{\mathrm{CO}_{2}}, V_{\mathrm{D}} / V_{\mathrm{T}}$ and microcirculatory parameters at baseline and $24 \mathrm{~h}$ after

\begin{tabular}{|c|c|c|c|}
\hline & Baseline & $24 \mathrm{~h}$ & $p$ \\
\hline \multicolumn{4}{|l|}{ Hemodynamics } \\
\hline $\mathrm{HR}$, bpm & $104(94-121)$ & $100(89-115)$ & 0.43 \\
\hline $\mathrm{MAP}, \mathrm{mmHg}$ & $74(69-87)$ & $75(67-92)$ & 0.35 \\
\hline CVP, mmHg, n & $12(8-14)$ & $12(7-14)$ & 0.96 \\
\hline $\mathrm{PAOP}, \mathrm{mmHg}, \mathrm{n}$ & $14(12-16), 22$ & $19(16-22), 24$ & 0.03 \\
\hline PAPm, mmHg, $\mathrm{n}$ & $36(42-46), 22$ & $30(26-41), 24$ & 0.13 \\
\hline PVR, dyn.s/ $\mathrm{cm}^{5}, \mathrm{n}$ & 298 (250-440), 22 & 299 (211-360), 24 & 0.86 \\
\hline Cardiac index, $\left(1 / \mathrm{min} / \mathrm{m}^{2}\right), n$ & $4.2(3.4-4.5), 22$ & $3.9(3.5-4.4), 24$ & 0.30 \\
\hline Norepinephrine, (ugr/kg/min), n & $0.10(0.05-0.27), 18$ & $0.05(0.03-0.34), 18$ & 0.09 \\
\hline \multicolumn{4}{|c|}{ Respiratory mechanics and blood gases } \\
\hline$V_{T}, \mathrm{ml}$ & $369(325-415)$ & $363(312-404)$ & 0.56 \\
\hline$V_{T}, \mathrm{ml} / \mathrm{kg}$ & $6.5(6.1-6.9)$ & $6.6(6.4-6.9)$ & 0.56 \\
\hline $\mathrm{RR}$ & $24(20-26)$ & $25(22-27)$ & 0.17 \\
\hline PEEP & $12(10-15)$ & $12(10-14)$ & 0.07 \\
\hline$P_{\text {Peak }}$ & $30(27-33)$ & $29(26-34)$ & 0.57 \\
\hline $\mathrm{Pm}_{\mathrm{aw}}$ & $19(14-21)$ & $18(15-20)$ & 0.36 \\
\hline$V_{T} / C_{R S}$ & $17(14-19)$ & $16(14-18)$ & 0.42 \\
\hline $\mathrm{pH}$ & $7.28(7.21-7.32)$ & $7.35(7.26-7.39)$ & $<0.001$ \\
\hline $\mathrm{PaO}_{2}, \mathrm{mmHg}$ & 79.1 (69.7-95.5) & $86.6(72.6-109.2)$ & 0.06 \\
\hline $\mathrm{PaCO}_{2}, \mathrm{mmHg}$ & 46.6 (39.9-56.3) & $42.3(34.6-47.6)$ & 0.003 \\
\hline $\mathrm{HCO}_{3}, \mathrm{mmol} / \mathrm{L}$ & $20.9(19.1-24.2)$ & $20.7(17.8-26.5)$ & 0.78 \\
\hline $\mathrm{BE}, \mathrm{mmol} / \mathrm{L}$ & $-6.4(-8.8$ to -2.3$)$ & $-5.9(-8.4$ to -0.05$)$ & 0.03 \\
\hline $\mathrm{PaO}_{2} / \mathrm{FiO}_{2}$ & $119(93-148)$ & $173(124-222)$ & $<0.001$ \\
\hline $\mathrm{PvO}_{2}, \mathrm{mmHg}$ & $48.7(42.3-54.1)$ & $40.8(36.9-47.6)$ & 0.004 \\
\hline $\mathrm{PvCO}_{2}, \mathrm{mmHg}$ & $48.2(41.6-59.3)$ & $44.6(36.1-53.6)$ & 0.003 \\
\hline $\mathrm{ScvO}_{2}, \%$ & $78.0(70.9-80.9)$ & $75.2(62.3-81.7)$ & 0.17 \\
\hline \multicolumn{4}{|l|}{ Capnography/expired $\mathrm{CO}_{2}$} \\
\hline$P_{\mathrm{ECO}_{2}}, \mathrm{mmHg}(\mathrm{BTPS})$ & $21.2(18.4-24.6)$ & $19.3(14.8-21.6)$ & 0.01 \\
\hline $\mathrm{F}_{\mathrm{ECO}}$ & $0.034(0.029-0.039)$ & $0.030(0.023-0.034)$ & 0.01 \\
\hline$V_{\mathrm{CO}_{2}}, \mathrm{ml} / \mathrm{min}(\mathrm{STPD})$ & $320(250-405)$ & $259(201-380)$ & 0.28 \\
\hline$V_{\mathrm{TE}}, \mathrm{ml}$ & $372(325-415)$ & $302(240-440)$ & 0.39 \\
\hline$V_{D} / V_{T}$ & $54(45-61)$ & $51(47-61)$ & 0.44 \\
\hline \multicolumn{4}{|c|}{ Microcirculatory blood flow parameters } \\
\hline PPV, \% & $69.6(57.8-79.2)$ & $75.7(62.8-81.5)$ & 0.01 \\
\hline LVP, \% & $90.9(82.3-96.5)$ & $90.3(85.3-96.8)$ & 0.52 \\
\hline $\mathrm{FCD}, n$ vessels $/ \mathrm{mm}^{2}$ & $6.6(5.1-7.5)$ & $6.9(5.5-8.2)$ & 0.03 \\
\hline $\mathrm{TCD}, n$ vessels $/ \mathrm{mm}^{2}$ & $11.6(10.8-12.6)$ & $12.3(11.0-13.3)$ & 0.08 \\
\hline $\mathrm{MFI}$ & $2.35(2.08-2.50)$ & $2.35(2.20-2.60)$ & 0.06 \\
\hline Heterogeneity index & $0.38(0.27-0.65)$ & $0.28(0.19-0.45)$ & 0.08 \\
\hline
\end{tabular}

HR: heart rate; MAP: mean arterial pressure; CVP: central venous pressure; PAOP: pulmonary artery occlusion pressure; PAPm: mean pulmonary artery pressure; PVR: pulmonary vascular resistance; $V_{T}$ : tidal volume; PEEP: positive end-expiratory pressure; $P_{\text {Peak }}$ : peak respiratory pressure; $\mathrm{Pm}_{\text {aw }}:$ mean pressure of the airway; $V_{\mathrm{T}} / C_{\mathrm{RS}}$ : tidal volume to respiratory system compliance (driving pressure); $\mathrm{PaO}_{2}$ : arterial oxygen partial pressure; $\mathrm{PaCO}_{2}:$ arterial carbon dioxide partial pressure; $\mathrm{HCO}_{3}$ : bicarbonate; $\mathrm{BE}$ : base excess; $\mathrm{PaO}_{2} / \mathrm{FiO}_{2}$ ratio: arterial oxygen partial pressure to oxygen inspiratory fraction; $\mathrm{PvO}_{2}$ : venous oxygen partial pressure; $\mathrm{PvCO}_{2}$ : venous carbon dioxide partial pressure; $\mathrm{SVO}_{2}$ : venous hemoglobin oxygen saturation; $P_{\mathrm{ECO}}$ : exhaled carbon dioxide pressure; $\mathrm{BTPS}$ : body temperature, and pressure, saturated; STPD: standard temperature and pressure, dry; $\mathrm{FECO}_{2}$ : exhaled carbon dioxide fraction; $V_{\mathrm{TE}}$ : exhaled tidal volume; $V_{\mathrm{D}} / V_{\mathrm{T}}$ : pulmonary dead-space fraction; PPV: percentage of small vessels perfused; LVP: percentage of large vessels perfused; FCD: functional capillary density; TCD: total capillary density; MFI: microvascular blood flow index 

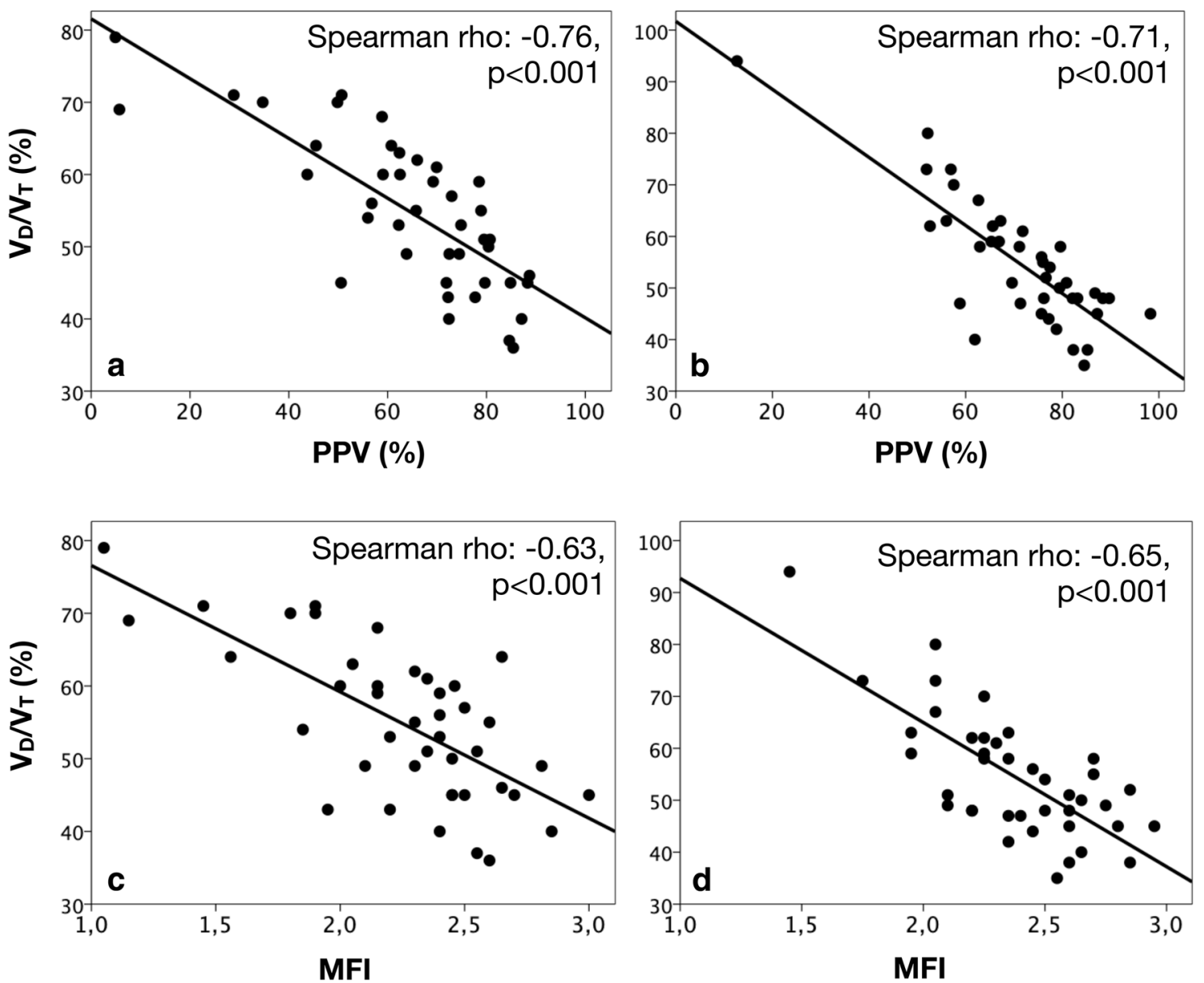

Fig. 1 Relationships between pulmonary dead-space fraction $\left(V_{D} / V_{T}\right)$ and the microcirculatory blood flow at baseline and $24 \mathrm{~h}$ after. a Scatter plot depicting the correlation between pulmonary dead-space fraction $\left(V_{D} / V_{T}\right)$ and the proportion of small vessels perfused at baseline. $\mathbf{b}$ Scatter plot depicting the correlation between pulmonary dead-space fraction $\left(V_{D} / V_{T}\right)$ and the proportion of small vessels perfused $24 \mathrm{~h}$ after. $\mathbf{c}$ Scatter plot depicting the correlation between pulmonary dead-space fraction $\left(V_{D} / V_{T}\right)$ and MFI at baseline. $\mathbf{d}$ Scatter plot depicting the correlation between pulmonary dead-space fraction $\left(V_{D} / V_{T}\right)$ and MFI $24 \mathrm{~h}$ after. PPV: percentage of small vessels perfused; $V_{D} V_{T}$ : pulmonary dead-space fraction; $H I$ : heterogeneity index of microcirculatory blood flow; MFI: microcirculatory blood flow index

$\left(V_{\mathrm{T}} / C_{\mathrm{RS}}\right)$ do not; (b) $V_{\mathrm{D}} / V_{\mathrm{T}}$ variations were closely related with dynamic changes in the microcirculatory blood flow distribution observed at sublingual mucosa.

Other mechanisms unrelated to shunt-induced hypoxemia could be implicated in gas exchange abnormalities and in the onset of pulmonary and extra-pulmonary multiorgan dysfunction in ARDS. Distribution of ventilation to poorly perfused $\left(10<V_{\mathrm{A}} / Q<100\right)$, severely hypoperfused $\left(V_{\mathrm{A}} / Q>100\right)$ or non-perfused, i.e., true dead-space ventilation $\left(V_{\mathrm{A}} / Q \sim \infty\right)$ lung units, can also contribute to gas exchange disturbances and it might be a key piece in the pathophysiology of ARDS. Some studies in the past demonstrated the occurrence of increased pulmonary dead-space fraction in patients with acute hypoxemic respiratory failure $[3,22,23]$, and highlighted the apparent relationship between high $V_{\mathrm{D}} / V_{\mathrm{T}}$ and increased mortality [8]. Nevertheless, early studies included patients under non-lung-protective ventilation strategies, in which overinflation leading to capillary collapse could explain $V_{\mathrm{A}} / Q$ mismatching with the resultant increased $V_{\mathrm{D}} / V_{\mathrm{T}}$ [24]. Remarkably, later studies in ARDS patients subjected to lung-protective ventilation, also demonstrated the occurrence of increases in $V_{\mathrm{D}} / V_{\mathrm{T}}$ and confirmed its consistent relationship with worse clinical outcomes $[9,10,25]$. In agreement with this, we observed increases in $V_{\mathrm{D}} / V_{\mathrm{T}}$ at baseline and $24 \mathrm{~h}$ after in patients with moderate and severe ARDS. Importantly, we did not find any relationship between $V_{\mathrm{D}} / V_{\mathrm{T}}$ and variables suggesting vascular collapse related to alveolar overdistention or increased pulmonary strain (e.g., $V_{\mathrm{T}} / C_{\mathrm{RS}}$ ), although admittedly, 
controlling airway pressures and $V_{\mathrm{T}} / C_{\mathrm{RS}}$ (driving pressure) could not prevent alveolar overdistention because the inhomogeneous lung compromise in ARDS [26].

Relationships between microvascular blood flow and $V_{\mathrm{D}} / V_{\mathrm{T}}$ have not been widely studied because of technical limitations to directly evaluate pulmonary microcirculation [15]. Our data suggest an apparent relationship between microcirculatory dysfunction and dead-space ventilation. Admittedly, sublingual mucosa and pulmonary circulation are two dissimilar vascular beds with particular regulating mechanisms. Nevertheless, during inflammatory conditions, microcirculatory dysfunction is a generalized phenomenon involving simultaneously most vascular beds [14], although with different effects depending on the territory studied [27]. Microcirculatory alterations have been described in autopsies and biopsies from lungs of patients with acute hypoxemic respiratory failure $[28,29]$ and angiograms performed through pulmonary artery catheters demonstrated filling defects attributable to macro- and micro-emboli [30, 31]. Increases in $V_{\mathrm{D}} / V_{\mathrm{T}}$ in our patients were well correlated with alterations in microcirculatory blood flow distribution detected in a non-pulmonary vascular bed. Such observation could pose the hypothesis about heterogeneity of microvascular blood flow contributing to inequalities in $V_{\mathrm{A}} / Q$ relationships. Indeed, variations of $V_{\mathrm{D}} / V_{\mathrm{T}}$ from baseline to $24 \mathrm{~h}$ after were closely related with dynamic changes in microcirculatory blood flow distribution at sublingual mucosa, which reinforce the strength of such relation. Nevertheless, whether pulmonary microvascular alterations or other organ-specific microvascular blood flow can be evaluated or estimated through evaluation of an extra-pulmonary microvascular bed can result highly controversial [15].

In normal conditions, heterogeneity of microvascular blood flow is negligible [12] and matching of perfusion to metabolism usually improves during hypoxic or low-flow states [32]. However, during inflammatory conditions, heterogeneity of microcirculation increases as consequence of the interruption of blood flow of individual capillaries causing derangements in the oxygen extraction capabilities, thus contributing to organ failure.
In agreement with this, we observed important microcirculatory alterations consisting in decreased PPV, reduced FCD and increased heterogeneity of blood flow, which were in turn linked to more severe extra-pulmonary organ dysfunction quantified by SOFA score (see Additional file 1: Table S3).

Pathophysiological mechanisms increasing $V_{\mathrm{D}} / V_{\mathrm{T}}$ in ARDS are quite complex. An increased $V_{\mathrm{D}} / V_{\mathrm{T}}$ reflects a global assessment of abnormal gas exchange, but not simply the contribution of discrete high $V_{\mathrm{A}} / Q$ regions and true anatomic dead space $\left(V_{\mathrm{A}} / Q \sim \infty\right)$. Although the patchy pattern of vascular damage is a phenomenon clearly recognized in ARDS [26], no studies demonstrated that damaged areas necessarily receive substantial ventilation, as would be necessary to explain regions of high $V_{\mathrm{A}} / Q$ ratio. Using the multiple inert gas elimination technique (MIGET) to evaluate the fractional contribution of each $V_{\mathrm{A}} / Q$ abnormality (shunt, mid-range $V_{\mathrm{A}} / Q$ heterogeneity, high $V_{\mathrm{A}} / Q$, and anatomic dead space) on total $V_{\mathrm{D}} / V_{\mathrm{T}}$ at progressively high PEEP levels, Coffey et al. [33] demonstrated similar $V_{\mathrm{D}} / V_{\mathrm{T}}$ values at different PEEP levels mediated by very different physiologic abnormalities, although certainly, higher PEEP values were consistently related to high $V_{\mathrm{A}} / Q$ peaks. Our results might add more complexity to the pathophysiology on increased $V_{\mathrm{D}} / V_{\mathrm{T}}$ in ARDS suggesting the contribution of altered microcirculatory blood flow distribution on the increase of high $V_{\mathrm{A}} / Q$ units.

Routine assessment of pulmonary gas exchange in ARDS is based on analysis of oxygen and carbon dioxide partial pressures. These variables, although sensitive to intrapulmonary factors (e.g., shunt and $V_{\mathrm{A}} / Q$ matching), could be also altered by extra-pulmonary elements such as cardiac output, oxygen consumption, minute ventilation and inspired oxygen fraction.

$V_{\mathrm{D}} / V_{\mathrm{T}}$ values can widely vary according to the method used to estimate it [34]. Previous studies used the Enghoff modification of the Bohr equation ( $\left.\mathrm{VD}_{\text {Enghoff }}\right)$ in patients with ARDS [8-10, 25]. Nevertheless, this method could overestimate the real $V_{\mathrm{D}} / V_{\mathrm{T}}$ when anatomic or intrapulmonary shunts are present as it assumes a perfect $V_{\mathrm{A}} / Q$ matching throughout all alveolar-capillary units [35, 36].

\section{(See figure on next page.)}

Fig. 2 Relationships between pulmonary dead-space fraction $\left(V_{D} / V_{T}\right)$ and some respiratory mechanics and oxygen parameters at baseline and $24 \mathrm{~h}$ after. a Scatter plot depicting the correlation between pulmonary dead-space fraction $\left(V_{D} / V_{T}\right)$ and the $\mathrm{PaO}_{2} / \mathrm{FiO}_{2}$ ratio at baseline. b Scatter plot depicting the correlation between pulmonary dead-space fraction $\left(V_{\mathrm{D}} / V_{\mathrm{T}}\right)$ and the $\mathrm{PaO}_{2} / \mathrm{FiO}_{2}$ ratio $24 \mathrm{~h}$ after. $\mathbf{c}$ Scatter plot depicting the correlation between pulmonary dead-space fraction $\left(V_{D} / V_{T}\right)$ and PEEP levels at baseline. $\mathbf{d}$ Scatter plot depicting the correlation between pulmonary dead-space fraction $\left(V_{D} / V_{T}\right)$ and PEEP levels $24 \mathrm{~h}$ after. e Scatter plot depicting the correlation between pulmonary dead-space fraction $\left(V_{D} / V_{T}\right)$ and the $V_{T} / C_{R S}$ at baseline. $\mathbf{f} S c a t t e r$ plot depicting the correlation between pulmonary dead-space fraction $\left(V_{D} / V_{T}\right)$ and the $V_{T} / C_{R S} 24 \mathrm{~h}$ after. $\mathbf{g}$ Scatter plot depicting the correlation between pulmonary dead-space fraction $\left(V_{D} / V_{T}\right)$ and $\mathrm{Pm}_{\mathrm{aw}}$ at baseline. $\mathbf{h}$ Scatter plot depicting the correlation between pulmonary dead-space fraction $\left(V_{\mathrm{D}} / V_{\mathrm{T}}\right)$ and $\mathrm{Pm}_{\mathrm{aw}} 24 \mathrm{~h}$ after. $\mathrm{PaO}_{2} / \mathrm{FiO}_{2}$ ratio: arterial oxygen partial pressure to oxygen inspiratory fraction; PEEP: positive end-expiratory pressure; $V_{T} / C_{R S}$ : tidal volume-to-respiratory system compliance ratio (i.e., driving pressure); $\mathrm{Pm}_{\text {aw: }}$ : mean pressure of the airway 

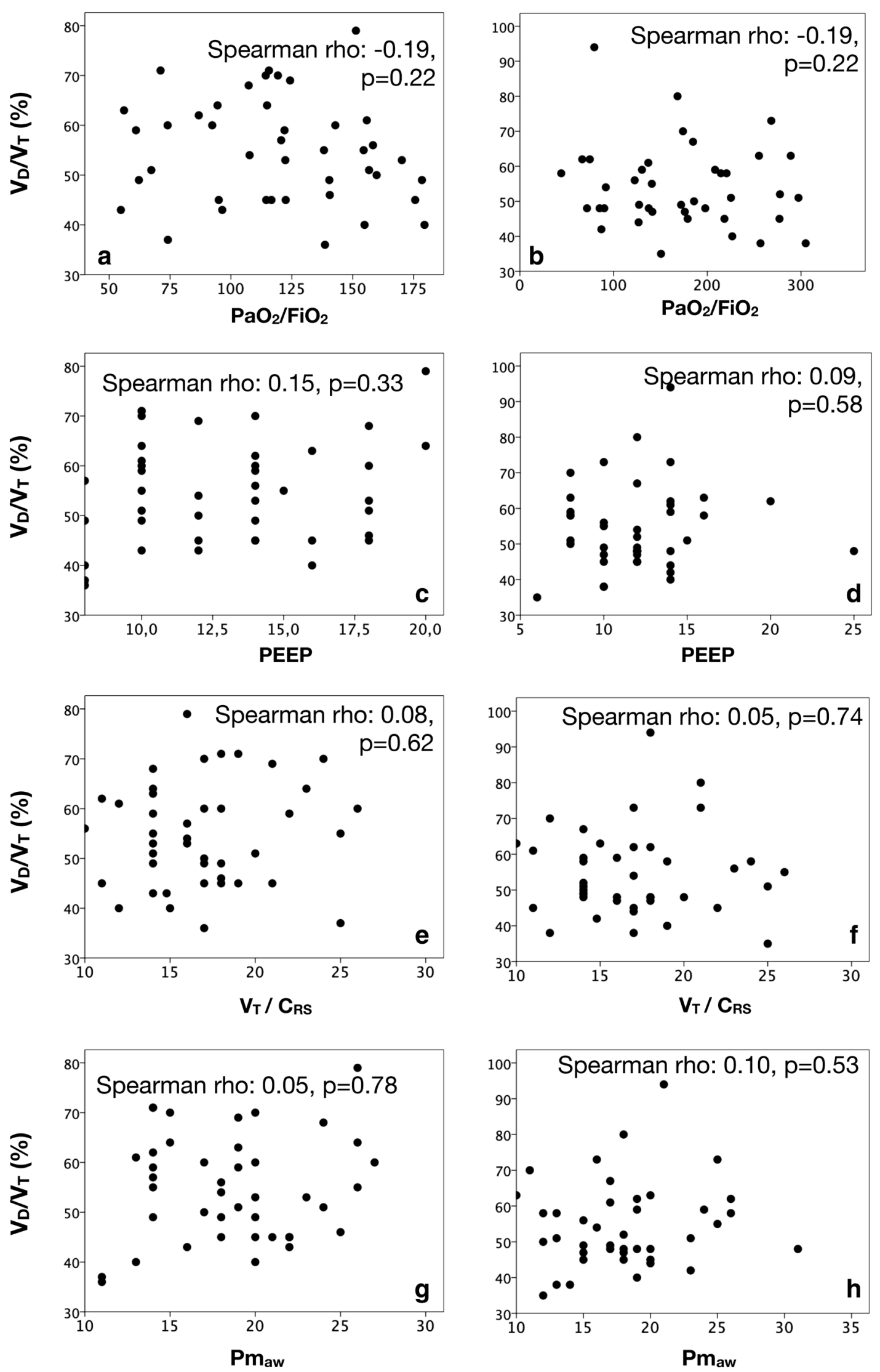


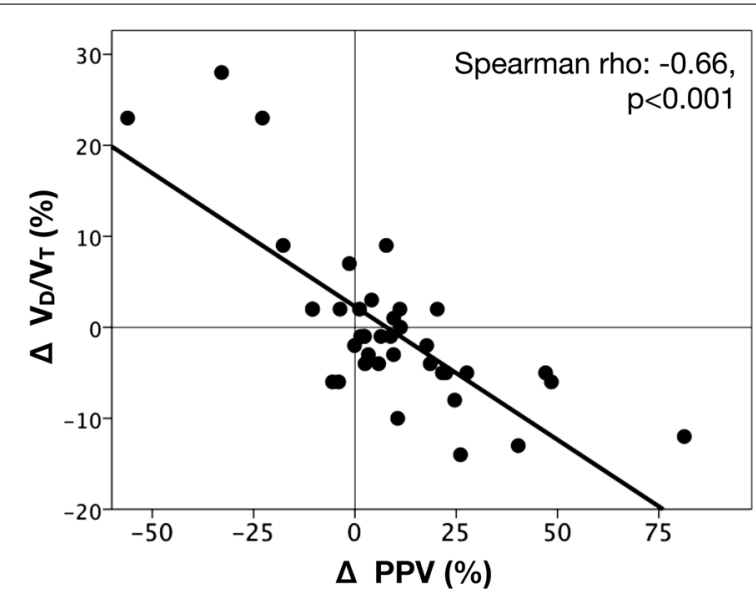

Fig. 3 Relationships between dynamic variations in pulmonary dead-space fraction $\left(V_{D} / V_{T}\right)$ and microcirculatory blood flow. Scatter plot depicting the correlation between variations in pulmonary dead-space fraction $\left(\Delta-V_{D} / V_{T}\right)$ vs. percentage of change in small vessels perfused ( $\triangle-P P V)$ between baseline and $24 \mathrm{~h}$ after

Although we used the $\mathrm{VD}_{\text {Enghoff }}$ method, we computed $V_{\mathrm{D}} / V_{\mathrm{T}}$ from the $\mathrm{CO}_{2}$ production $\left(V_{\mathrm{CO}_{2}}\right)$ and $\mathrm{CO}_{2}$ exhaled fraction $\left(F_{\mathrm{ECO}_{2}}\right)$ measurements by volumetric capnography, which can accurately reflect measurements by metabolic monitors [20].

Trying to exclude cases with transitory hypoxemia simulating ARDS, we completed a two-step selection previously described $[16,17]$. Although breathing pure oxygen may influence the $V_{\mathrm{A}} / Q$ distribution [5], our definitive $V_{\mathrm{D}} / V_{\mathrm{T}}$ measurements were performed $60 \mathrm{~min}$ after return to the previous $\mathrm{FiO}_{2}$, thus causing the lowest impact on $V_{\mathrm{A}} / Q$ balance. Also, we used a stepwise recruitment maneuver with progressive PEEP increases, which was part of the local protocol at the time in which patients were included. Probably at present, such maneuver would not be used as recent evidence suggests that it can be harmful [37]. Nevertheless, such maneuver allowed us to standardize the selection of PEEP and ventilatory parameters.

We recognize that our study has important limitations. First, many hemodynamic and respiratory coexisting factors can influence $V_{\mathrm{D}} / V_{\mathrm{T}}$ measurements. Indeed, combination of hypovolemia, vasoactive agents and/or inotropics, cardiac output variations, pulmonary resistances and flows, distribution of ventilation along the lungs and even local microthrombi formation, might influence $V_{\mathrm{D}} / V_{\mathrm{T}}$ variations in one or other direction. Thereby, identical $V_{\mathrm{D}} / V_{\mathrm{T}}$ elevations might reflect simultaneous alterations in diverse physiological components. Second, our study is not able to demonstrate a causal association between $V_{\mathrm{D}} / V_{\mathrm{T}}$ and sublingual microcirculation and it was not registered as observational study.
Nevertheless, dynamic variations from baseline to $24 \mathrm{~h}$ after merit exploration in future studies. Third, whether pulmonary microvascular alterations occur in parallel to other extra-pulmonary microvascular beds is highly controversial. However, microcirculation studies reveal simultaneous alterations at different beds during shock or inflammatory conditions. Fourth, the number of cases included in our study was relatively small. However, the fact that our patients were strictly selected and calculation of $V_{\mathrm{D}} / V_{\mathrm{T}}$ used $V_{\mathrm{CO}_{2}}$ and exhaled fraction of $\mathrm{CO}_{2}\left(F_{\mathrm{ECO}_{2}}\right)$ measurements by volumetric capnography strengthens our results.

\section{Conclusion}

Increased heterogeneity of microcirculatory blood flow evaluated at sublingual mucosa seems to be related to increases in $V_{\mathrm{D}} / V_{\mathrm{T}}$ independently of respiratory mechanics and oxygen parameters, thus suggesting that microcirculatory alterations could be implicated in ventilation/ perfusion mismatching during early ARDS.

The inverse dynamic relationships observed between sublingual microcirculation and dead-space ventilation poses a hypothetical pathophysiological mechanism during moderate and severe ARDS that deserves future research efforts.

\section{Supplementary information}

Supplementary information accompanies this paper at https://doi. org/10.1186/s13613-020-00651-1.

Additional file 1. Microcirculatory assessement.

\section{Abbreviations}

ARDS: Acute respiratory distress syndrome; $\mathrm{CO}_{2}$ : Carbon dioxide; COPD: Chronic obstructive pulmonary disease; $C_{R S}$ : Compliance of the respiratory system; $\mathrm{EtCO}_{2}$ : End-tidal $\mathrm{CO}_{2} ;$ FCD: Functional capillary density; $\mathrm{EECO}_{2}$ : Exhaled $\mathrm{CO}_{2}$ fraction; MFI: Microcirculatory flow index; $\mathrm{PaCO}_{\mathrm{a}}$ : Arterial $\mathrm{CO}_{2}$ partial pressure; $P_{\mathrm{ECO}}$ : Exhaled $\mathrm{CO}_{2}$ pressure; PEEP: Positive end-expiratory pressure; PPV: Percentage of small-vessels perfused; TCD: Total capillary density; $V_{A} / Q$ : Ventilation-to-perfusion ratio; $V_{\mathrm{CO}_{2}}: \mathrm{CO}_{2}$ production; $V_{\mathrm{D}} / V_{\mathrm{T}}$ : Dead-space ventilation fraction; $V_{\mathrm{E}}$ : Exhaled minute ventilation; $V_{\mathrm{T}}$ :Tidal volume; $V_{T} / V_{\mathrm{RS}}$ : Driving pressure.

\section{Acknowledgements}

The authors thank Dr. Fernando Rosso (CIC, Fundación Valle del Lili-Universidad Icesi, Cali, Colombia) and Dr. Yuri Takeuchi (Universidad Icesi - Fundación Valle del Lili) for their unconditional support to this project.

\section{Authors' contributions}

Literature search: GAOT, DFB and GH; data acquisition: GAOT, DFB, JDV, WFB, and HJM; data analysis and interpretation: GAOT, GH, HJM, JDV, WFB, EQ, LECT; critical review: GAOT, GH, AB and DDB; conception, hypothesis delineation, and design of the study: GAOT, and DDB. All authors read and approved the final manuscript.

\section{Funding}

The current study received logistic support from the Centro de Investigaciones Clínicas - Fundación Valle del Lili, Cali - Colombia. 


\section{Availability of data and materials}

The datasets generated and/or analyzed during the current study are not publicly available as recommended by the local Ethical and research committee involving human beings (Fundación Valle del Lili, Cali, Colombia) but these could be available from the corresponding author on reasonable request and under prior approval by such committee.

\section{Ethics approval and consent to participate}

The ethical and research committee involving human beings approved the current study (Protocol number: 0628; Approval Number: 038-7, 2013, Fundación Valle del Lili, Cali, Colombia).

\section{Consent for publication}

\section{Not applicable.}

\section{Competing interests}

The authors declare that they have no competing interests.

\section{Author details}

1 Department of Intensive Care, Fundación Valle del Lili - Universidad ICESI, Av. Simón Bolívar Cra. 98, Cali, Valle del Cauca, Colombia. ${ }^{2}$ Translational Medicine Laboratory for Critical Care and Advanced Trauma Surgery, Fundación Valle del Lili - Universidad Icesi, Cali, Colombia. ${ }^{3}$ Departamento de Medicina Intensiva, Pontificia Universidad Católica de Chile, Santiago, Chile. ${ }^{4}$ Department of Intensive Care, CHIREC Hospitals, Université Libre de Bruxelles, Brussels, Belgium.

Received: 29 October 2019 Accepted: 16 March 2020

Published online: 24 March 2020

\section{References}

1. Ranieri VM, Rubenfeld GD, Thompson BT, Ferguson ND, Caldwell E, Fan $E$, et al. Acute respiratory distress syndrome: the Berlin Definition. JAMA. 2012:307(23):2526-33

2. Dantzker DR, Brook CJ, Dehart P, Lynch JP, Weg JG. Ventilation-perfusion distributions in the adult respiratory distress syndrome. Am Rev Respir Dis. 1979;120(5):1039-52.

3. Ralph DD, Robertson HT, Weaver LJ, Hlastala MP, Carrico CJ, Hudson LD. Distribution of ventilation and perfusion during positive end-expiratory pressure in the adult respiratory distress syndrome. Am Rev Respir Dis. 1985;131(1):54-60.

4. Matamis D, Lemaire F, Harf A, Teisseire B, Brun-Buisson C. Redistribution of pulmonary blood flow induced by positive end-expiratory pressure and dopamine infusion in acute respiratory failure. Am Rev Respir Dis. 1984;129(1):39-44.

5. Radermacher P, Maggiore SM, Mercat A. Fifty years of research in ARDS. Gas exchange in acute respiratory distress syndrome. Am J Respir Crit Care Med. 2017;196(8):964-84

6. Murray JF, Matthay MA, Luce JM, Flick MR. An expanded definition of the adult respiratory distress syndrome. Am Rev Respir Dis. 1988;138(3):720-3.

7. Bernard GR, Artigas A, Brigham KL, Carlet J, Falke K, Hudson L, et al. The American-European Consensus Conference on ARDS. Definitions, mechanisms, relevant outcomes, and clinical trial coordination. Am J Respir Crit Care Med. 1994;149(3 Pt 1):818-24.

8. Nuckton TJ, Alonso JA, Kallet RH, Daniel BM, Pittet JF, Eisner MD, et al. Pulmonary dead-space fraction as a risk factor for death in the acute respiratory distress syndrome. N Engl J Med. 2002;346(17):1281-6.

9. Cepkova M, Kapur V, Ren X, Quinn T, Zhuo H, Foster E, et al. Pulmonary dead space fraction and pulmonary artery systolic pressure as early predictors of clinical outcome in acute lung injury. Chest. 2007;132(3):836-42

10. Kallet RH, Zhuo H, Ho K, Lipnick MS, Gomez A, Matthay MA. Lung injury etiology and other factors influencing the relationship between deadspace fraction and mortality in ARDS. Respir Care. 2017;62(10):1241-8.

11. Dueck R, Wagner PD, West JB. Effects of positive end-expiratory pressure on gas exchange in dogs with normal and edematous lungs. Anesthesiology. 1977;47(4):359-66.
12. Zuurbier CJ, van Iterson M, Ince C. Functional heterogeneity of oxygen supply-consumption ratio in the heart. Cardiovasc Res. 1999:44(3):488-97.

13. De Backer D, Creteur J, Preiser JC, Dubois MJ, Vincent JL. Microvascular blood flow is altered in patients with sepsis. Am J Respir Crit Care Med. 2002;166(1):98-104

14. De Backer D, Ospina-Tascon G, Salgado D, Favory R, Creteur J, Vincent JL. Monitoring the microcirculation in the critically ill patient: current methods and future approaches. Intensive Care Med. 2010;36(11):1813-25.

15. Ware LB, Matthay MA. Measuring microvascular blood flow in sepsis-a continuing challenge. Lancet. 2002;360(9341):1187-8.

16. Villar J, Pérez-Méndez L, López J, Belda J, Blanco J, Saralegui I, et al. An early $\mathrm{PEEP} / \mathrm{FIO}$, trial identifies different degrees of lung injury in patients with acute respiratory distress syndrome. Am J Respir Crit Care Med. 2007;176(8):795-804.

17. Ferguson ND, Kacmarek RM, Chiche JD, Singh JM, Hallett DC, Mehta $S$, et al. Screening of ARDS patients using standardized ventilator settings: influence on enrollment in a clinical trial. Intensive Care Med. 2004;30(6):1111-6.

18. de Matos GF, Stanzani F, Passos RH, Fontana MF, Albaladejo R, Caserta RE, et al. How large is the lung recruitability in early acute respiratory distress syndrome: a prospective case series of patients monitored by computed tomography. Crit Care. 2012;16(1):R4.

19. Borges JB, Okamoto VN, Matos GF, Caramez MP, Arantes PR, Barros F, et al. Reversibility of lung collapse and hypoxemia in early acute respiratory distress syndrome. Am J Respir Crit Care Med. 2006;174(3):268-78.

20. Siobal MS, Ong H, Valdes J, Tang J. Calculation of physiologic dead space: comparison of ventilator volumetric capnography to measurements by metabolic analyzer and volumetric $\mathrm{CO}_{2}$ monitor. Respir Care. 2013;58(7):1143-51

21. De Backer D, Hollenberg S, Boerma C, Goedhart P, Büchele G, OspinaTascon G, et al. How to evaluate the microcirculation: report of a round table conference. Crit Care. 2007;11(5):R101.

22. Lamy M, Fallat RJ, Koeniger E, Dietrich HP, Ratliff JL, Eberhart RC, et al. Pathologic features and mechanisms of hypoxemia in adult respiratory distress syndrome. Am Rev Respir Dis. 1976;114(2):267-84.

23. Gattinoni L, Bombino M, Pelosi P, Lissoni A, Pesenti A, Fumagalli R, et al. Lung structure and function in different stages of severe adult respiratory distress syndrome. JAMA. 1994;271(22):1772-9.

24. Hedenstierna G, White FC, Mazzone R, Wagner PD. Redistribution of pulmonary blood flow in the dog with PEEP ventilation. J Appl Physiol Respir Environ Exerc Physiol. 1979;46(2):278-87.

25. Kallet RH, Zhuo H, Liu KD, Calfee CS, Matthay MA, Investigators NHLaBIAN The association between physiologic dead-space fraction and mortality in subjects with ARDS enrolled in a prospective multi-center clinical trial. Respir Care. 2014;59(11):1611-8.

26. Cressoni M, Cadringher P, Chiurazzi C, Amini M, Gallazzi E, Marino A, et al. Lung inhomogeneity in patients with acute respiratory distress syndrome. Am J Respir Crit Care Med. 2014;189(2):149-58.

27. van Genderen ME, Klijn E, Lima A, de Jonge J, Sleeswijk Visser S, Voorbeijtel J, et al. Microvascular perfusion as a target for fluid resuscitation in experimental circulatory shock. Crit Care Med. 2014;42(2):e96-105.

28. Greene R, Zapol WM, Snider MT, Reid L, Snow R, O'Connell RS, et al. Early bedside detection of pulmonary vascular occlusion during acute respiratory failure. Am Rev Respir Dis. 1981;124(5):593-601.

29. Zapol WM, Kobayashi K, Snider MT, Greene R, Laver MB. Vascular obstruction causes pulmonary hypertension in severe acute respiratory failure. Chest. 1977;71(2 suppl):306-7.

30. Bachofen M, Weibel ER. Alterations of the gas exchange apparatus in adult respiratory insufficiency associated with septicemia. Am Rev Respir Dis. 1977;116(4):589-615.

31. Tomashefski JF, Davies P, Boggis C, Greene R, Zapol WM, Reid LM. The pulmonary vascular lesions of the adult respiratory distress syndrome. Am J Pathol. 1983:112(1):112-26.

32. Stein JC, Ellis CG, Ellsworth ML. Relationship between capillary and systemic venous $\mathrm{PO}_{2}$ during nonhypoxic and hypoxic ventilation. Am J Physiol. 1993;265(2 Pt 2):H537-42.

33. Coffey RL, Albert RK, Robertson HT. Mechanisms of physiological dead space response to PEEP after acute oleic acid lung injury. J Appl Physiol Respir Environ Exerc Physiol. 1983;55(5):1550-7. 
34. Doorduin J, Nollet JL, Vugts MP, Roesthuis LH, Akankan F, van der Hoeven $J G$, et al. Assessment of dead-space ventilation in patients with acute respiratory distress syndrome: a prospective observational study. Crit Care. 2016;20(1):121.

35. Kuwabara S, Duncalf D. Effect of anatomic shunt on physiologic deadspace-to-tidal volume ratio_-a new equation. Anesthesiology. 1969;31(6):575-7.

36. Tusman G, Sipmann FS, Bohm SH. Rationale of dead space measurement by volumetric capnography. Anesth Analg. 2012;114(4):866-74.

37. Cavalcanti AB, Suzumura É, Laranjeira LN, Paisani DM, Damiani LP, Guimarães HP, et al. Effect of lung recruitment and titrated positive end-expiratory pressure (PEEP) vs low PEEP on mortality in patients with acute respiratory distress syndrome: a randomized clinical trial. JAMA. 2017;318(14):1335-45.

\section{Publisher's Note}

Springer Nature remains neutral with regard to jurisdictional claims in published maps and institutional affiliations.

\section{Submit your manuscript to a SpringerOpen ${ }^{\odot}$ journal and benefit from:}

- Convenient online submission

- Rigorous peer review

- Open access: articles freely available online

- High visibility within the field

- Retaining the copyright to your article

Submit your next manuscript at $\boldsymbol{\Delta}$ springeropen.com 